\title{
Comparison of "Onlay" and "Sublay" Methods of Mesh Repair of Incisional Hernia in Terms of Early and Late Period Wound Complications
}

\author{
Gülten Çiçek Okuyan ${ }^{1}$, $\odot$ Yılmaz Bilsel ${ }^{2}$
}

${ }^{1}$ Department of General Surgery, Haydarpasa Numune Training and Research Hospital, Istanbul, Turkey

${ }^{2}$ Department of General Surgery, Bezmialem University Dragos Hospital, Istanbul, Turkey

\begin{abstract}
Introduction: Different approaches are used depending on placement of mesh in the surgical treatment of incisional hernia. These methods have controversial results in terms of wound complications and recurrence. In this study, it was aimed to compare open mesh repair of incisional hernia using the approaches of "onlay" and "sublay" mesh placement in terms of complications and recurrence.

Methods: Patients who underwent mesh repair of incisional hernia in our hospital for a 2-year retrospective study were evaluated. The patients were divided into two groups according to the placement of the polypropylene mesh: "onlay" (Group $\mathrm{O}, \mathrm{n}=27$ ) and "sublay" (Group S, n=25). Demographic and clinical data of the patients were recorded. Postoperative early (seroma, hematoma, wound infection) and late (chronic pain, recurrence) complications were compared between groups. Results: There were 52 patients in the study with a mean age of $60.4 \pm 12$ years. There was no difference between the groups in terms of demographic and clinical characteristics ( $p>0.05)$. The mean duration of the surgery in Group $S$ was significantly longer than Group O ( $p=0.02$ ). Although the length of hospital stay was longer in Group $\mathrm{S}$, there was no significant difference between the two groups in terms of the length of hospital stay ( $p=0.067)$. There was no significant difference between the groups in terms of early and late wound complications ( $p>0.05)$.

Discussion and Conclusion: There is no significant difference between early and late wound complications after mesh repair of incisional hernia with "onlay" and "sublay" methods. Both methods can be applied with similar efficacy and safety. Keywords: Complication; hernia repair; incisional hernia; polypropylene; surgical mesh.
\end{abstract}

$\mathrm{T}$ he development of an incisional hernia after abdominal surgery is an important complication. Rates of up to $20 \%$ have been reported in previously published series $^{[1-3]}$. Although this rate is related to clinical features such as the patient's age, obesity, co-morbidities and the type of surgery performed, the physical characteristics of the graft used in the repair and surgical techniques are also considered to be important factors for the development of hernia ${ }^{[1,2]}$.

Graft-assisted open methods have been used for the surgical treatment of incisional hernia for many years. In addition to incisional hernia repairs with laparoscopic and robotic approaches in recent years, hernia repair surgeries using composite and biological grafts are also per-

Correspondence (İletişim): Gulten Cicek Okuyan, M.D. Haydarpasa Numune Egitim ve Arastirma Hastanesi, Genel Cerrahi Bolumu, Istanbul, Turkey

Phone (Telefon): +90 5327613520 E-mail (E-posta): dr.cicekgulten@gmail.com

Submitted Date (Başvuru Tarihi): 30.03.2021 Accepted Date (Kabul Tarihi): 21.04.2021

Copyright 2021 Haydarpaşa Numune Medical Journal

OPEN ACCESS This is an open access article under the CC BY-NC license (http://creativecommons.org/licenses/by-nc/4.0/) 
formed $^{[4-7]}$. However, the open method is still the most commonly used incisional hernia repair technique due to the need for advanced technology and high cost grafts and the difficulty of applying it to complex hernias with extensive tissue loss ${ }^{[1,8]}$.

During the repair of the incisional hernia with the open method, the graft is fixed to different anatomical layers of the abdominal wall. These different repair techniques can be grouped as "onlay", "inlay", "underlay" and "sublay"[1,2,9]. Open incisional hernia repair with graft using the "sublay" method is accepted as the gold standard method by some authors ${ }^{[4,5]}$. This method is also reported as one of the two most commonly used methods with laparoscopic incisional hernia repair ${ }^{[6]}$. However, which method is more effective and safe in the surgical treatment of incisional hernia is controversial.

Postoperative complications and recurrence are closely related to where the graft is placed ${ }^{[9]}$. However, previous studies did not show the superiority of different techniques over each other ${ }^{[3,9]}$. In addition, no significant differences were reported in terms of recurrence and infection rate in the systematic reviews of the publications about the "sublay" and "onlay" graft technique ${ }^{[10,11]}$. On the other hand, it is thought that "sublay" grafts cause less seroma formation $^{[12]}$. Despite the high complication rate of "onlay" graft repair, it is also reported that it causes less recurrence ${ }^{[13]}$. Considering the current publications, the long-term effects of placing grafts in different layers of the abdominal wall are still not fully elucidated.

In this study, it was aimed to compare open incisional hernia repairs with graft performed with "onlay" and "sublay" approaches in terms of postoperative complication development and recurrence rates in the long-term follow-up period.

\section{Materials and Methods}

\section{Study}

This study included patients with incisional hernia who underwent surgical treatment in the General Surgery Clinic in a two-year retrospective study in our hospital. The authors conducted the study in accordance with the Declaration of Helsinki. Written informed consent was obtained from all patients.

\section{Patients}

The diagnosis of incisional hernia was confirmed by physical examination and, if necessary, by abdominal ultra- sonography or computed tomography. Patients with an incisional hernia with a defect diameter greater than 10 $\mathrm{cm}$ were evaluated for the study. Inclusion criteria for incisional hernia were, repair of incisional hernia using "onlay" and "sublay" methods using polypropylene graft, completion of the follow-up period after surgical treatment, and patient age of 18 and over. Exclusion criteria were emergency surgery, metastatic disease, chronic liver disease and ascites, incisional hernia repair using a method other than "onlay" and "sublay" grafting, and lack of patient consent.

A total of 60 patients who met the inclusion criteria were identified. During the follow-up period, two patients were excluded from the study due to lack of data, five patients died from other causes, and one patient was diagnosed with metastatic ovarian cancer requiring surgery in the second year after surger. Among the remaining 52 patients, 27 patients who underwent onlay (Group O) graft repair and 25 patients who underwent sublay (Group S) graft repair were included in the study.

Demographic data of the patients [age, gender, body mass index (BMI)], previous abdominal surgeries and incisional hernia repairs, American Society of Anesthesiologists (ASA) score, diameter of the defect $(\mathrm{cm})$, duration of operation (minutes), intraoperative blood loss $(\mathrm{mL})$, length of hospital stay (days) and complications were recorded for each patient separately.

\section{Surgical Technique}

In the "onlay" technique, after the protruding part of the hernia sac was resected, the posterior and anterior rectus sheath were closed with a continuous absorbable suture (0/0 PDS) together with the peritoneum. After the polypropylene graft was placed on the rectus sheath at least $5 \mathrm{~cm}$ from the edges, it was sutured with non-absorbable interrupted stitches (2/0 Prolene). The procedure was completed by placing a drain on the graft.

In the "sublay"technique, the polypropylene graft was placed retromuscularly between the rectus muscle and the posterior rectus sheath, and between the posterior rectus and the peritoneum in the lower abdomen, at a distance of at least 5 $\mathrm{cm}$ in all directions from the defect margins. The grafts were stitched with interrupted 2/0 polypropylene sutures, with the nodes remaining in the subcutaneous fat tissue.

\section{Follow-up}

The patients were examined for complications daily during their hospital stay. Postoperative complications were classified according to Clavien-Dindo Classification. Stage II 
and above complications were considerably evaluated ${ }^{[14]}$. Drain removal was performed when the daily drainage amount was $20 \mathrm{ml}$ or less.

Postoperative seromas or hematomas were defined by clinical examination. Abdominal ultrasonography was performed in suspicious cases. To support the abdominal region, patients were advised to use a corset for 2-6 months. After the operation, the patient was prohibited from doing heavy work for 6 months. After the operation, the patient was prohibited from doing heavy work for 6 months.

In the first six months after the operation, the patients were examined for the development of complications in the outpatient clinic controls, which were performed every 6-8 weeks. After this date, patients were invited to annual outpatient controls.

If a swelling or defect was palpated along the incision line on physical examination, this was considered a recurrence. In suspected cases, recurrence was confirmed by ultrasonography or computed tomography. Surgical treatment of the patient due to recurrence in another center was also considered as recurrence.

Serous fluid or blood collections requiring aspiration or percutaneous treatment at the surgical site after drain removal were defined as seroma and hematoma. Purulent discharge from the wound along with redness at the incision line was considered a wound infection. In the postoperative period, discomfort or pain related to the incision line that interferes with daily activities was defined as chronic pain.

\section{Statistical Analysis}

In summarizing the data obtained from the study, descriptive statistics were tabulated as mean \pm standard deviation and median, and minimum-maximum, depending on the distribution for continuous variables. Statistical evaluation of differences between groups and hernia recurrence was performed using the $x^{2}$ test and Kruskal-Wallis tests. Differences with $p<0.05$ were considered significant. Statistical analyzes were performed with SPSS 16 (SPSS Inc. Released 2007. SPSS for Windows, Version 16.0. Chicago, SPSS Inc.).

\section{Results}

The mean age of the patients included in the study was $58.7 \pm 11$ years in Group O, $60.2 \pm 12$ years in Group S, and the gender distribution was as follows: 12 (23\%) males and 15 (29\%) females in Group O; 16 (30.8\%) males and 9 (17.3\%) females In Group S. The BMI value was $34 \pm 6$ in Group $O$ and $38 \pm 5$ in Group S. Recurrent incisional hernia was detected in $14(26.9 \%)$ patients (Group O 50\%, Group S 50\%). The mean defect size was $14 \pm 2 \mathrm{~cm}$ in Group $O$ and $13 \pm 2 \mathrm{~cm}$ in Group S, with mean ASA scores of II and III, respectively. Demographic and clinical characteristics of the patients are given in Table 1. No significant differences were found between the groups in terms of age, gender, BMI and ASA scores ( $p>0.05$ for all).

There was a significant difference between the two groups in terms of duration of operation ( $p=0.02)$. The mean operation time (170 $\pm 80 \mathrm{~min}$ ) of the patients in Group S was significantly longer than the operation time (115 $\pm 45 \mathrm{~min})$ of the patients in Group O. Although the hospital stay was longer in Group S, there was no significant difference between the two groups in terms of length of hospital stay (9.2 \pm 3.4 days and $7.9 \pm 2.3$ days, $p=0.067)$. Other characteristics related to treatment are given in Table 2 .

The mean value of follow-up was 49 months (median 4 years, range 39-67 months). The distribution of complications according to general and groups is given in Table 3. Mortality secondary to pulmonary embolism occurred in one patient in Group S within 30 days postoperatively. The overall mortality rate was $1.9 \%$. Postoperative bleeding occurred in three patients. The minimum and maximum value range of the number of blood transfusions to the patients was three and six. Wound complications were detected in nine patients (17.3\%). Wound infection developed in five patients. Seroma and hematoma were seen in two patients each. There was no significant difference between the groups in terms of wound complications ( $p>0.05$ ). All

Table 1. Demographic and clinical characteristics

\begin{tabular}{|c|c|c|}
\hline Parameters & $\begin{array}{c}\text { Group } 0 \\
\mathbf{n}=27\end{array}$ & $\begin{array}{c}\text { Group } S \\
n=25\end{array}$ \\
\hline Age $(\text { years) })^{\dagger}$ & $58.7 \pm 11$ & $60.2 \pm 12$ \\
\hline \multicolumn{3}{|l|}{ Gender ${ }^{\ddagger}(\%)$} \\
\hline Male & $12(23)$ & $16(30.8)$ \\
\hline Female & $15(29)$ & $9(17.3)$ \\
\hline BMI $\left(\mathrm{kg} / \mathrm{m}^{2}\right)^{\dagger}$ & $34 \pm 6$ & $38 \pm 5$ \\
\hline \multicolumn{3}{|l|}{ Primary surgery type ${ }^{\ddagger}(\%)$} \\
\hline Elective & $22(81.4)$ & $15(60)$ \\
\hline Urgent & $5(18.6)$ & $10(40)$ \\
\hline \multicolumn{3}{|c|}{ Recurrent incisional hernia ${ }^{\ddagger}(\%)$} \\
\hline After primary repair & $1(3.7)$ & $1(4)$ \\
\hline After onlay repair & $4(14.8)$ & $6(24)$ \\
\hline After sublay repair & $2(7.4)$ & 0 \\
\hline Colostomy presence ${ }^{\ddagger}(\%)$ & $4(14.8)$ & $2(8)$ \\
\hline Defect size $(\mathrm{cm})^{\dagger}$ & $14 \pm 2$ & $13 \pm 2$ \\
\hline
\end{tabular}


Table 2. Distribution of treatment outcomes by groups

\begin{tabular}{lccc}
\hline Parameters & $\begin{array}{c}\text { All patients } \\
\mathbf{n = 5 2}\end{array}$ & $\begin{array}{c}\text { Group 0 } \\
\mathbf{n = 2 7}\end{array}$ & $\begin{array}{c}\text { Group S } \\
\mathbf{n = 2 5}\end{array}$ \\
\hline $\begin{array}{l}\text { Duration of operation (min) } \\
\text { Average blood transfusion (units) }\end{array}$ & $155 \pm 55$ & $115 \pm 45$ & $170 \pm 80$ \\
Simultaneous surgeries ${ }^{\ddagger}(\%)$ & 0.2 & 0 & 0.2 \\
$\quad$ Colostomy closure & & & \\
$\quad$ Abdominoplasty & $6(11.5)$ & $4(14.8)$ & $2(8)$ \\
$\quad$ Cholecystectomy & $4(7.7)$ & $3(11)$ & $1(4)$ \\
Length of stay in hospital (days) $^{\dagger}$ & $2(3.8)$ & $1(3.7)$ & $1(4)$ \\
Average follow-up time (months) (\%) & $8.4 \pm 8.5$ & $7.9 \pm 2.3$ & $9.2 \pm 3.4$ \\
\hline${ }^{\dagger:}$ Mean \pm standard deviation; ${ }^{\ddagger}: \mathrm{n}(\%)$. & $49(39-67)$ & $49(39-67)$ & $49(39-67)$ \\
\hline
\end{tabular}

Table 3. Distribution of complications by groups

\begin{tabular}{lccc}
\hline Complications & $\begin{array}{c}\text { All patients } \\
\mathbf{n = 5 2} \\
\mathbf{( \% )}\end{array}$ & $\begin{array}{c}\text { Group O } \\
\mathbf{n = 2 7} \\
\mathbf{( \% )}\end{array}$ & $\begin{array}{c}\text { Group S } \\
\mathbf{n = 2 5} \\
\mathbf{( \% )}\end{array}$ \\
\hline Pulmonary embolism $^{\ddagger}$ & $1(1.9)$ & $0(0)$ & $1(4)$ \\
Postoperative bleeding $^{\ddagger}$ & $3(5.8)$ & $1(3.7)$ & $2(8)$ \\
Wound complications $^{\ddagger}$ & $9(17.3)$ & $5(18.5)$ & $4(16)$ \\
$\quad$ Wound infection & $5(9.6)$ & $3(11.1)$ & $2(8)$ \\
$\quad$ Seroma & $2(3.8)$ & $1(3.7)$ & $1(4)$ \\
$\quad$ Hematoma & $2(3.8)$ & $1(3.7)$ & $1(4)$ \\
Chronic pain & $6(11.5)$ & $2(7.4)$ & $4(16)$ \\
Recurrence & $7(13.5)$ & $4(14.8)$ & $3(12)$ \\
$\leq 1$ year & $0(0)$ & $0(0)$ & $0(0)$ \\
$1-2$ years & $2(3.8)$ & $1(3.7)$ & $1(4)$ \\
$\geq 2$ year & $5(9.6)$ & $3(11.1)$ & $2(8)$ \\
\hline${ }_{*} \mathrm{n}(\%)$. & & &
\end{tabular}

wound complications in the groups were treated with a conservative approach.

Six patients (11.5\%) reported chronic pain at the incision site. Four patients with chronic pain were in Group $S$ and two patients were in Group O. Hernia recurrence developed in seven patients (13.5\%) during the follow-up period. No recurrence was detected within the first year. Two of the recurrences were seen after 1-2 years and five after 2 years. Although the recurrence rate was higher in Group $O$ than in Group S, there was no significant difference between them $(p=0.79)$. While recurrence was observed in four $(28.5 \%)$ of 14 patients who underwent surgery for recurrent incisional hernia, it was seen in three $(7.8 \%)$ of 38 patients who underwent primary incisional hernia repair. There was a correlation between early postoperative complications and recurrence. Recurrence developed in five (38\%) patients with early complications, compared to $5 \%$ for patients without any wound complications.

\section{Discussion}

In this study, it was shown that there was no significant difference in complications, including recurrence, in the early postoperative period and after a mean follow-up period of 49 months after incisional hernia repair with a graft performed with the "sublay" and "onlay" graft placement technique. Although the duration of operation and hospital stay were longer in patients who were operated with the "sublay" graft technique, the similarity between early and late complications were evaluated as the equivalent efficacy of the two methods in incisional hernia repair with grafts.

In the surgical treatment of incisional hernia, some recommendations can be considered regarding the placement of the graft in different anatomical layers. If the hernia extends to the suprapubic region, it is suggested that the "sublay" method would be more appropriate as it allows 
graft fixation to the deep areas of the pelvis. Likewise, if the hernia is in the upper quadrant of the abdomen, it is thought that less seroma formation and an effective graft fixation will be possible with the "onlay" method without the need for large dissection areas ${ }^{[8,15]}$. For this reason, it does not seem right to make a more precise statement about the superiority of two different methods to each other. Randomized studies are needed to clearly demonstrate this distinction.

Wound complications such as wound infection, seroma and hematoma can be seen at varying rates after incisional hernia repair. Such complications are evaluated in relation to the tissue dissection width and the graft material used ${ }^{[1]}$. In some studies, the "onlay" method is stated to cause seroma and hematoma formation more frequently ${ }^{[13]}$. In the study conducted by Acar et al. ${ }^{[1]}$, the development of seroma and hematoma after the "onlay" graft method was detected in $15.7 \%$ of the patients. This rate was found as $3.8 \%$ for seroma and $3.8 \%$ for hematoma for surgeries performed with the same method in our study. The relatively lower rate of seroma and hematoma in this study was thought to be related to the surgical technique. It can be considered as a strong possibility that the clinical characteristics of the patient and hernia, surgical technique and graft differences may cause different results in previously published studies.

In a meta-analysis comparing the "sublay" and "onlay" methods in the surgical treatment of incisional hernia, "sublay" method was stated to be more effective than the "onlay" method in terms of recurrence and wound infection ${ }^{[16]}$. In a systematic review and meta-analysis of four different graft placement techniques ("onlay", "inlay", "sublay" and "underlay"), the lowest rates of recurrence, wound infection and other wound complications were seen after the "sublay" method ${ }^{[9]}$. In another systematic review comparing repairs for giant incisional hernias ( $>15$ $\mathrm{cm})$, it has been shown that the "sublay" method was the most advantageous approach with the component separation method ${ }^{[3]}$. Although prospective studies with large participation are needed to reveal the advantages and disadvantages of each method, it can be concluded that the "sublay" method is a more effective and safe approach than other methods by using these data.

The development of recurrence after incisional hernia repair is considered as another important complication. A generally accepted relationship between different graft placement techniques and recurrence rates cannot be demonstrated ${ }^{[1]}$. Studies have different results on this is- sue. High recurrence rates of up to $24 \%$ are reported with the standard "sublay" technique ${ }^{[5]}$. In the series of 1078 cases published by Cano-Valderrama et al. ${ }^{[13]}$, the "onlay" method has not been shown to lead to a higher rate of recurrence. Hawn et al. ${ }^{[17]}$ reported a $28.5 \%$ recurrence rate in a median follow-up period of 73.4 months in a 1346case incisional hernia series. The open or laparoscopic "underlay" method was concluded to be the most successful method in terms of recurrence. Having the same follow-up period as our study, Acar et al. ${ }^{[1]}$ in their study offound the recurrence rate as $5.8 \%$ after the "onlay" graft method. On the other hand, our recurrence rate was $14.8 \%$ in the "onlay" method and $12 \%$ in the "sublay" method. Although the recurrence rate was higher in patients who underwent recurrent incisional hernia repair and developed early wound complications, statistical significance could not be examined due to the number of cases. Although the recurrence rates in the study were within the range specified in the literature, it was thought that the number of patients who had recurrent incisional hernia repair might have an impact on this rate. In addition, it should not be overlooked that the recurrence rates may increase with the increase in the follow-up period ${ }^{[5]}$.

The lack of power analysis for the sample size and the relatively small number of patients were considered as limitations. In addition, patients who were operated in other centers due to recurrence, being evaluated as recurrence, was considered as another limitation.

In conclusion, incisional hernia repairs with graft using "onlay" and "sublay" methods are surgical treatment options with similar early and late wound complication rates, as well as similar efficacy and safety rates.

Ethics Committee Approval: Retrospective study.

Peer-review: Externally peer-reviewed.

Authorship Contributions: Concept: G.Ç.O., Y.B.; Design: G.Ç.O.; Collection or Processing: G.Ç.O.; Analysis or Interpretation: G.Ç.O.,Y.B.; Literature Search: G.Ç.O.; Writing: G.Ç.O.

Conflict of Interest: None declared.

Financial Disclosure: The authors declared that this study received no financial support.

\section{References}

1. Acar T, Acar N, Sür Y, Kamer E, Atahan K, Genç H, et al. The effects of operation technique on recurrence of incisional hernia repair. Sisli Etfal Hastan Tip Bul 2020;54:23-8. [Turkish] [CrossRef]

2. Abdollahi A, Maddah GH, Mehrabi BM, Jangjoo A, Forghani $M N$, Sharbaf N. Prosthetic incisional hernioplasty: clinical experience with 354 cases. Hernia 2010;14:569-73. [CrossRef] 
3. Eriksson A, Rosenberg J, Bisgaard T. Surgical treatment for giant incisional hernia: a qualitative systematic review. Hernia 2014;18:31-8. [CrossRef]

4. Chand B, Indeck $M$, Needleman B, Finnegan M, Van Sickle KR, Ystgaard $B$, et al. A retrospective study evaluating the use of Permacol ${ }^{\mathrm{TM}}$ surgical implant in incisional and ventral hernia repair. Int J Surg 2014;12:296-303. [CrossRef]

5. Ayik N, Klein P, Grützmann R, Demir R. Long-term Outcome of incisional hernia repairs using the Erlangen Inlay Onlay Mesh (EIOM) Technique. J Surg Res 2019;243:14-22. [CrossRef]

6. Köckerling F, Hoffmann H, Mayer F, Zarras K, Reinpold W, Fortelny $\mathrm{R}$, et al. What are the trends in incisional hernia repair? Real-world data over 10 years from the Herniamed registry. Hernia 2021;25:255-65. [CrossRef]

7. Martín-Cartes JA, Tamayo-López MJ, Bustos-Jiménez M. 'Sandwich' technique in the treatment of large and complex incisional hernias. ANZ J Surg 2016;86:343-7. [CrossRef]

8. Kingsnorth AN, Sivarajasingham N, Wong S, Butler M. Open mesh repair of incisional hernias with significant loss of domain. Ann R Coll Surg Engl 2004;86:363-6. [CrossRef]

9. Holihan JL, Nguyen DH, Nguyen MT, Mo J, Kao LS, Liang MK. Mesh location in open ventral hernia repair: a systematic review and network meta-analysis. World J Surg 2016;40:89-99.

10. Ibrahim R, Abounozha $S$, Alshehri T. Is the surgical site infection rate higher in sublay or onlay mesh repair of incisional hernia? Ann Med Surg (Lond) 2021;62:200-2. [CrossRef]
11. Ibrahim $R$, Alshehri $T$, Abounozha $S$. Is the recurrence rate of incisional hernia is affected by mesh positioning? Ann Med Surg (Lond) 2021;62:92-4. [CrossRef]

12. Ibrahim R, Abounozha S, Kheder A, Alshahri T. Incidence of seroma in sublay versus onlay mesh repair of incisional hernia. Ann Med Surg (Lond) 2020;61:155-7. [CrossRef]

13. Cano-Valderrama O, Porrero JL, Quirós E, Bonachia O, Castillo MJ, Cervantes N, et al. Is onlay polypropylene mesh repair an available option for incisional hernia repair? a retrospective cohort study. Am Surg 2019;85:183-7. [CrossRef]

14. Rogmark P, Petersson U, Bringman S, Eklund A, Ezra E, Sevonius $D$, et al. Short-term outcomes for open and laparoscopic midline incisional hernia repair: a randomized multicenter controlled trial: the ProLOVE (prospective randomized trial on open versus laparoscopic operation of ventral eventrations) trial. Ann Surg 2013;258:37-45. [CrossRef]

15. Hasbahceci M, Basak F. Interposition of the hernia sac as a protective layer in repair of giant incisional hernia with polypropylene mesh. Surg Today 2014;44:227-32. [CrossRef]

16. Timmermans L, de Goede B, van Dijk SM, Kleinrensink GJ, Jeekel J, Lange JF. Meta-analysis of sublay versus onlay mesh repair in incisional hernia surgery. Am J Surg 2014;207:980-8.

17. Hawn MT, Snyder CW, Graham LA, Gray SH, Finan KR, Vick CC. Long-term follow-up of technical outcomes for incisional hernia repair. J Am Coll Surg 2010;210:648-55. [CrossRef] 